\title{
AGGRESSION, EMPATHY, AND LIFE SATISFACTION DURING THE COVID-19 PANDEMIC AMONG STUDENTS IN PRIVATE HIGHER EDUCATION
}

\author{
Katarina Sokići, \\ Fayyaz Hussain Qureshi' ${ }^{2}$, \\ Sarwar Khawaja ${ }^{3}$ \\ ${ }^{1}$ Dr., Research Associate, \\ Oxford Business College, \\ 65 George Street, Oxford, \\ United Kingdom \\ orcid.org/0000-0001-7522-1228 \\ ${ }^{2}$ Dr., Director of Research and Quality Assurance, \\ Oxford Business College, \\ 65 George Street, Oxford, \\ United Kingdom \\ orcid.org/0000-0003-1305-9493 \\ ${ }^{3}$ Chairman Business Development, \\ Oxford Business College, \\ 65 George Street, Oxford, \\ United Kingdom
}

\begin{abstract}
:
The primary purpose of this study was to investigate relationships between aggression, empathy, and life satisfaction during the COVID-19 pandemic. The main aim was to analyse the contribution of empathy components (empathic concern, personal distress, perspective-taking, and fantasy) above reactive and proactive aggression in predicting life satisfaction. The Reactive-Proactive Aggression Questionnaire (RPQ), Interpersonal Reactivity Index (IRI), Satisfaction with Life Scale (SWLS), Single Item on Overall Life Satisfaction (OLS), and Single Item on Overall Happiness $(\mathrm{OH})$ measures were applied to 418 students in private higher education (232 male, 186 female). The participants' age ranged from 18 to 34 , with a mean age of 21 years $(S D=3.18)$. Results showed that reactive aggression negatively predicted satisfaction with life and overall happiness, while proactive aggression did not significantly predict indicators of life satisfaction. Empathic concern showed a significant positive effect on satisfaction with life, while personal distress showed a significant adverse effect on all indicators of life satisfaction. Aggression and empathy together accounted for $14 \%$ of the variance in the satisfaction with life and $5 \%$ of the variance in overall life satisfaction and overall happiness.
\end{abstract}

i Correspondence: email katarina.sokić@oxfordbusinesscollege.ac.uk, fayyaz.qureshi@oxfordbusinesscollege.ac.uk, sarwar.khawaja@oxfordbusinesscollege.ac.uk 
Empathy added incremental variance in explaining life satisfaction after controlling for aggression. The results highlight the importance of reactive aggression and emotional empathy in the explanation of life satisfaction.

Keywords: reactive aggression, proactive aggresion, empathy, life satisfaction, COVID 19, private higher education

\section{Introduction}

The COVID-19 pandemic disrupted individuals' quality of life and psychosocial functioning in many aspects of their lives. Reduced social contacts, lockdown, fear for health and existence, uncertainty around the long-term implications of COVID-19, and blocking of goals are circumstances that lead to frustration. The frustration-aggression hypothesis based on the psychodynamic approach (Dollard \& Ford, 1939) proposed that frustration leads to aggression. A longitudinal study of mental health and well-being in the UK during the COVID-19 pandemic on 3077 adults conducted in three waves between the spring and autumn 2020 (O'Connor et al., 2020) has shown increased rates of suicidal ideation among young adults (18-29 years), and moderate to severe levels of depressive symptoms and loneliness. These results were similar for ethnic minorities and White in the UK.

All levels of education, including private higher education, have been influenced by COVID-19 limitations, including rapid adaptations to virtual learning (Qureshi et al., 2020), and a significant reduction of social contacts between students and professors.

During the COVID-19 pandemic, college students experienced psychological distress related to high anxiety, depression, low sleep quality, and stress which reduced life satisfaction and personal wellbeing as a whole (Duond, 2021; Evans et al., 2021; White, 2021). A recent study conducted by $\mathrm{Hu}$ et al. (2021) on a large sample of Chinese college students has shown that empathy increases the effect of hope (i.e. perceived ability to achieve goals) on post-stress growth, defined as re-establishing psychological balance after stressful or traumatic events. These results imply that empathy can play a significant role in increasing desired outcomes and decreasing undesired outcomes.

The impact of the pandemic on aggression and aggressive behaviour among the student population is not well explored. However, it is reasonable to expect that aggression can contribute to maladaptive anti-social behaviours, including anger and hostility, lower protective behaviours, and breaking "social distancing" rules to avoid spreading infection. Given the above findings and given that the role of aggression and empathy in predicting life satisfaction has not been sufficiently examined, one aim of this study was to contribute to a better understanding of these relationships. We are particularly interested in whether aggression moderates relationships between affective and cognitive empathy components and life satisfaction among students in private higher education. 


\section{Literature review}

\subsection{Aggression and life satisfaction}

Aggression is a complex phenomenon that has been defined as a behaviour performed with the intent to hurt or harm others (Coie \& Dodge, 1997; Crick \& Grotpeter, 1995). There are different forms of aggressive behaviour (e.g., physically, verbally, overt, indirectly, etc.) that pertain to the ways aggression is expressed. In order to understand the specific impact of aggression on social relations, it is essential to distinguish the forms of aggression and the different functions of aggression: reactive and proactive aggression (Poulin \& Boivin, 2000). According to Dodge \& Coie (1987), the function of reactive aggressive behaviour is to mitigate the threat (perceived or imagined) but not to achieve some assigned goal. On the other hand, reactive aggression is a reaction to an external stimulus subjectively interpreted as a provocation, threat, frustration, or prevention of achieving a goal). Reactive aggressive behaviour is violent and impulsive, accompanied by hostile facial expressions, negative affect, and the loss of control (Poulin \& Boivin, 2000). Contrary, proactive aggression is instrumental, predatory, planned, "coldblooded", occurs regardless of provocation due to anticipation of a desirable goal or due to domination over others (Dodge \& Coie, 1987; Raine et al., 2006).

Aggression is often investigated in the context of antisocial, criminal behaviour, and concerning socially malevolent personality traits called the Dark Triad (Machiavellianism, narcissism, and psychopathy). Studies have shown that both reactive and proactive aggression was associated with psychopathy (Cima et al., 2013; Dinić \& Wertag, 2018; Pechorro et al., 2015; Sokić, 2017), and Machiavellianism (Barlett, 2016; Dinić \& Wertag, 2018).

Previous studies have failed to sufficiently examine the relationship between aggression and life satisfaction indicators among the student population. Relationships between aggression and spiritual life satisfaction among the university students in Jordan indicated that high levels of spiritual well-being (meaning/peace and faith) significantly negatively related to physical and verbal aggression, hostility, and anger (Alorani \& Alradaydeh, 2017). The results of a study conducted by Çevik (2017) on university students in Turkey showed that satisfaction with life positively related to anger control and harmful to all anger dimensions (i.e. anger-out, and suppressed anger (anger-in).

Both reactive and proactive aggression positively correlated to social anxiety, trait anxiety, absence of close friends, and paranoid ideation (Raine et al., 2006), and so we can expect hostile relations between reactive and proactive aggression and indicators of life satisfaction.

\subsection{Empathy and life satisfaction}

Empathy is a multidimensional concept defined as the "reactions of one individual to the practical experiences of another" (Davis, 1983). Empathy includes the affective and cognitive components and has a central place in social interactions (Lawrence et al., 2004). The affective (emotional) component of empathy reflects the emotional response to the other 
person's mental state, while the cognitive component represents the cognitive assessment of the other person's perspective or mental state (Shamay-Tsoory et al., 2009). According to Davis (1983), empathy consists of four specific aspects: empathic concern and personal distress (an emotional component of empathy), and perspective-taking and fantasy (a cognitive component of empathy). Empathic concern represents feelings for others and should be related to sensitivity and emotionality. Personal distress represents a tendency to adopt the psychological point of view of others and should be associated with anxiety and low self-esteem. Perspective-taking help to anticipate the behaviour and understand the emotional states of others, and therefore should be positively related to better social functioning and rewarding interpersonal relationships. Fantasy reflects a tendency to identify with characters in fictional situations (movies, books) and help others; therefore, it may be associated with emotionality (Davis, 1980; Davis, 1983). Previous studies have shown a positive association between empathy and happiness among students; scores on perspective-taking and compassionate care were significantly positively related to happiness scores (Ozcakir et al., 2016). Empathy is also related to good communication skills and optimism (Hojat et al., 2015). Different quality of life domains were positively correlated with perspective taking and personal distress scores (Paro et al., 2014).

\section{The study}

This study aims to extend the understanding of the relationships between aggression, empathy, and life satisfaction. The main goal of this study is to explore the contributions of empathy components above reactive and proactive aggression in predicting life satisfaction. Additionally, we will investigate the moderation (interacting) effect of proactive and reactive aggression on the relationship between empathy components and indicators of life satisfaction. Although there is a body of research linking aggression and life satisfaction as well as empathy and life satisfaction, to the best of our knowledge, there is no study that has explored both aggression and empathy in the prediction of life satisfaction among students. In previous studies that explored aggression's contributions in the prediction of life satisfaction, aggression emerged as the strong negative predictor of life satisfaction (Alorani \& Alradaydeh, 2017; Çevik, 2017). However, these studies were not examined different functions of aggression.

Given that, in this study, we will examine the contributions of the different function aggression and affective and cognitive components of empathy in predicting life satisfaction indicators.

Since reactive aggression includes anger, hostility, frustration, impulsivity, antisociality, physical violence, low affiliation, poor relationships (Pechorro et al., 2015; Poulin \& Boivin, 2000), and good social relations are necessary for happiness (Diener \& Seligman, 2002), reactive aggression is expected to be negatively related to life satisfaction indicators.

Based on the theory that proactive aggression comprises dysregulated responsive emotional system and blunted affect (Raine et al., 2006), and empirical evidence showing 
that proactive aggression is related to psychopathy (Patrick, 2001), callous-unemotional traits (Frick et al, 2003), social adversity and parasitic lifestyle (Hare et al., 1999) proactive aggression is expected to be negatively related to life satisfaction indicators.

Out of the empathy components, we predict that empathic concern will have positive relations with an indicator of life satisfaction due to the theoretical assumption that empathic concern represents positive feelings for others, sensitivity, and emotionality (Davis, 1983). Since personal distress is theoretically linked to anxiety and low self-esteem, we predicted that scores on personal distress would be negatively associated with the indicators of life satisfaction (Davis, 1980; Davis, 1983).

Therefore, we expect that personal distress will remain a significant negative predictor of life satisfaction indicators. Since perspective-taking theoretically could help to understand the emotional states of others, better social functioning, and build good interpersonal relationships (Davis, 1983), we expect positive relations between perspective-taking and life satisfaction indicators.

\section{Methods}

\subsection{Participants and procedure}

The sample consisted of 418 students in private higher education colleges located in Zagreb (Croatia) (232 male, 186 female), majoring in entrepreneurship economics (60\%), tourism and hotel management (21\%), and engineering (19\%). The participants' age ranged from 18 to 34 , with a mean age of 21 years $(S D=3.18)$. Data were collected online during the lockdown in the first half of 2021. Students participated voluntarily, and testing was anonymous. All participants provided informed consent and were then asked to complete the self-report questionnaires. In addition, they were provided with detailed information about the purpose and procedure of the study and received no course credit for participation. The study protocol was authorised by the Research Ethics Panel of the Oxford Business College.

\subsection{Instruments}

\subsubsection{Aggression}

Aggression was measured by the Reactive-Proactive Aggression Questionnaire (RPQ; Raine et al., 2006). The RPQ is a self-report measure that distinguishes reactive and proactive aggression and consists of 23 items: 11 items which measure reactive aggression (e.g., How often have you reacted angrily when provoked by others, How often have you gotten angry when frustrated), and 12 items which measure proactive aggression (e.g., How often have you had fights with others to show who was on top, How often have you used physical force to get others to do what you want). In addition, the participants were asked how often they had ever engaged in a specific aggressive behaviour by using a three-point scale ( 0 - never; 1 - sometimes, or 2 - often). Total aggression scores are the sum of scores in proactive and reactive aggression scale scores. Confirmatory factor analysis showed a two-factor structure of the RPQ. In the current study, responses for 
these items ranged from 0 to 2 and demonstrated good internal reliability coefficients for the reactive aggression scale $(\alpha=.81)$ and the proactive aggression scale $(\alpha=.80)$.

\subsubsection{Empathy}

Empathy was assessed by the 28-item Interpersonal Reactivity Index (IRI; Davis, 1983). The IRI is a 28-item self-report instrument consisting of four separate, seven-item subscales designed to measure affective and cognitive dimensions of empathy. Affective dimension includes empathic concern (e.g., I often have tender, concerned feelings for people less fortunate than me), and personal distress (e.g., I sometimes feel helpless when I am in the middle of a very emotional situation) subscales. Cognitive dimension includes fantasy (e.g., When I watch a good movie, I can very easily put myself in the place of a leading character), and perspective-taking (e.g., I believe that there are two sides to every question and try to look at them both) subscales. The items are scored on a six-point scale (from $1=$ does not describe me to 6 = describes me very well). The IRI was translated and used in previous research in Croatia (Sokić, 2017; Sokić \& Wertag, 2018). In the present study, Cronbach's alpha coefficients for the empathic concern, personal distress, fantasy, and perspectivetaking subscales were .71, .71, 72 and .74, respectively. The IRI has demonstrated validity and stability correlating with other empathy tests (Davis \& Franzoi, 1991).

\subsubsection{Life satisfaction}

Life satisfaction was measured by the reviewed version of Satisfaction with Life Scale (SWLS, Pavot \& Diener, 1993), Single Item on Overall Life Satisfaction (OLS), and Single Item on Overall Happiness $(\mathrm{OH})$. The single-item happiness scale was found to be reliable and valid (i.e. psychometrically adequate) (Abdel-Khalek, 2006).

The Satisfaction with Life Scale estimates the cognitive component of subjective well-being, using 5 items (e.g. "The conditions of my life are excellent”, "So far I have gotten the important things I want in life") on a 7 point scale ranging from 1 (strongly disagree) to 7 (strongly agree). In this study, the SWLS showed adequate psychometric characteristics $(\alpha=.82)$. In an effort to verify the factor structure of the SWLS, we performed a principal-axis factor analysis. The analysis resulted in a single factor solution. This factor accounted for $50.85 \%$ of the variance of the scale.

A Single Item on Overall Life Satisfaction (OLS). This measure assesses overall life satisfaction by using the following question: "Taken all together, do you satisfied with your life?". Participants responded on a 0-10 scale with only the extreme values labelled 1 (completely dissatisfied) and 10 (completely satisfied).

A Single Item on Overall Happiness $(\mathrm{OH})$. This measure assesses overall happiness by using the following question: "Do you feel happy in general?" Participants responded on a $0-10$ scale with only the extreme values labelled 1 (minimum) and 10 (maximum). 


\section{Data analysis}

Zero-order correlations (the Pearson's correlation coefficient) were calculated to determine the relationship between aggression, empathy, and subjective well-being components, zero-order correlations (the Pearson's correlation coefficient) were calculated. In order to assess the relationships of each aggression dimension and empathy dimensions with life satisfaction indicators while controlling for the overlap with other aggression and empathy dimensions, three regression analyses were computed. After controling gender and age in Step 1, reactive and proactive aggression were entered in Step 2. Empathic concern, personal distress, fantasy and perspective-taking were entered in Step 3.

To test for possible gender differences in relations between aggression and empathy as predictors and subjective well-being variables as criteria, a hierarchical linear regression model was performed with gender entered at Step 1, aggression and empathy variables (reactive aggression, proactive aggression, empathic concern, personal distress, fantasy, and perspective-taking) entered at Step 2, and six gender $\mathrm{x}$ aggression/empathy interactions entered at Step 3. There was no significant increase in $R^{2}\left(R^{2} \Delta\right)$ on the third step for life satisfaction $(\Delta F[6,404]=0.55, p=.767)$, overall life satisfaction $(\Delta F[6,404]=$ $0.51, p=.803)$, and overall happiness $(\Delta F[6,404]=0.33, p=.923)$. These results have shown that no gender $x$ aggression/ empathy interaction was found. Given this, we reported findings for regression analyses for the whole sample (including male and female participants).

\section{Results}

\subsection{Descriptive statistics and the intercorrelations between all study variables}

Descriptive statistics, reliabilities, and bivariate correlations between the variables are displayed in Table 1. All scales and subscales demonstrated good internal consistency (Cronbach's alpha of .70 and above). Bivariate correlations showed that both functions of aggression were negatively related to perspective-taking and satisfaction with life. Reactive aggression was positively related to personal distress and fantasy. Also, reactive aggression was negatively related to overall life satisfaction and happiness, while proactive aggression was negatively related to empathic concern. Empathic concern was positively related to satisfaction with life, while personal distress was negatively related to satisfaction with life, overall life satisfaction, and overall happiness. On the bivariate level, perspective-taking was positively related to life satisfaction. Bivariate correlations of all variables with age were not statistically significant (ranging from 0.01 for personal distress to 0.07 for reactive aggression).

Since we found high correlations between predictor variables, we run multicollinearity diagnostics in each of the models by estimating variance inflation factors (VIF). The VIF value was 1.72 for reactive aggression, 1.74 for proactive aggression, 1.52 for empathic concern, 1.31 for personal distress, 1.19 for fantasy, and 1.33 
for perspective-taking. These results indicated that multicollinearity was not a problem in the present study because of VIF < 10 for all predictors (Vittinghoff et al., 2012).

Table 1: Descriptive statistics, internal reliability, and correlations for study variables $(\mathrm{N}=418)$

\begin{tabular}{|l|c|c|c|c|c|c|c|c|c|}
\hline Variables & $\mathbf{1 .}$ & $\mathbf{2 .}$ & $\mathbf{3 . ~ E C}$ & $\mathbf{4 . ~ P D}$ & $\mathbf{5 . ~ F}$ & $\mathbf{6 . ~ P T}$ & $\mathbf{7 .}$ & $\mathbf{8 .}$ & $\mathbf{9 .}$ \\
\hline 1. Reactive aggression & $\mathbf{( . 8 1 )}$ & & & & & & & & \\
\hline 2. Proactive aggression & $\mathbf{. 5 8}$ & $\mathbf{( . 8 0 )}$ & & & & & & & \\
\hline 3. Empathic concern & .02 & -.18 & $(\mathbf{7 2})$ & & & & & & \\
\hline 4. Personal distress &. $\mathbf{2 2}$ & .06 &. $\mathbf{4 0}$ & $\mathbf{( 7 1 )}$ & & & & & \\
\hline 5. Fantasy & $.11^{*}$ & -.08 &. $\mathbf{3 2}$ & $.17^{* *}$ & $\mathbf{( 7 2 )}$ & & & & \\
\hline 6. Perspective-taking & -.25 & -.31 &. $\mathbf{3 6}$ & -.02 &. $\mathbf{2 5}$ & $\mathbf{( 7 4 )}$ & & & \\
\hline 7. Satisfaction with life & -.20 & -.20 & $.12^{*}$ & -.23 & .06 &. $\mathbf{1 8}$ & $(.82)$ & & \\
\hline 8. Overall life satisfaction & $-.10^{*}$ & -.06 & -.07 & -.18 & -.09 & .01 & .52 & n.a. & \\
\hline 9. Overall happiness & $-.15^{* *}$ & -.04 & -.05 & $-.17^{* *}$ & -.07 & .03 &. $\mathbf{5 5}$ & .75 & n.a. \\
\hline Mean & 11.06 & 3.35 & 24.51 & 18.84 & 24.17 & 24.29 & 45.13 & 7.99 & 8.02 \\
\hline SD & 4.04 & 3.41 & 5.14 & 5.02 & 5.41 & 4.51 & 6.39 & 1.50 & 1.52 \\
\hline Note: Crona
\end{tabular}

Note: Cronbach alpha (i.e. internal reliability coefficients; $\alpha$ ) appear in parentheses along the main diagonal. Maximal range of response for reactive and proactive aggression scales: 0-23, empathic concern, personal distress, fantasy, and perspective-taking subscales: $1-5$, satisfaction with life scale: 1 -7 , and for overall life satisfaction and overall happiness: 0-10

n.a. = not applicable

Bolded values are significant at $p<.001,{ }^{* *} p<.01,{ }^{*} p<.05$ (two-tailed tests)

\subsection{Hierarchical linear regression analyses}

In order to test the predictive power of reactive and proactive dimensions of aggression and four empathy components (empathic concern, personal distress, fantasy, and perspective-taking) in explaining subjective well-being components (i.e. satisfaction with life, overall life satisfaction, and overall happiness, three hierarchical regression analyses were conducted. Gender and age were entered as control variables in the first step, aggression dimensions were entered in the second step, and the four empathy components were entered in the third step. Results of hierarchical regression analyses (see Table 2 ) showed that predictors together explained $14 \%$ of the variance in satisfaction with life $(\Delta F[6,409]=10.71, p<.001), 5 \%$ of the variance in overall life satisfaction $(\Delta F$ $[6,409]=3.59, p<.01)$, and $5 \%$ of the variance in overall happiness $(\Delta F[6,409]=3.58, p<$ $.01)$.

In the second step, the results showed that reactive aggression was a significant negative predictor of satisfaction with life and overall happiness, while proactive aggression had no significant contribution in the prediction of any components of subjective well-being. (Table 2). Percentage-wise, both dimensions of aggression together accounted for $5 \%$ of the variance in satisfaction with life, and $3 \%$ of the variance in overall happiness. In the third step, empathy components together accounted for an increase of $9 \%$ of the variance in satisfaction with life, $4 \%$ of the variance in overall life satisfaction, and $2 \%$ of the variance in overall happiness. In the third step, reactive aggression became a non-significant predictor of satisfaction with life. Also, reactive aggression remained a significant negative predictor of overall happiness. In both steps, proactive aggression 
had no significant contribution in the prediction of any components of subjective wellbeing. In the third step, the results showed that empathic concern uniquely positively predicted satisfaction with life, while personal distress negatively predicted all components of subjective well-being. The other two components of empathy (fantasy and perspective-taking) showed no significant contribution to predicting subjective wellbeing components.

Table 2: Hierarchical linear regression analysis: prediction of satisfaction with life, overall life satisfaction and overall happiness based on aggression and empathy $(\mathrm{N}=418)$

\begin{tabular}{|c|c|c|c|}
\hline & Satisfaction with life & Overall life satisfaction & Overall happiness \\
\hline & $\beta$ & $\beta$ & $\beta$ \\
\hline \multicolumn{4}{|l|}{ Step 1} \\
\hline Gender & .08 & .05 & .04 \\
\hline Age & .03 & -.03 & -.01 \\
\hline$R^{2}$ & .01 & .00 & .00 \\
\hline \multicolumn{4}{|l|}{ Step 2} \\
\hline Gender & .06 & .06 & .07 \\
\hline Age & .01 & -.04 & -.02 \\
\hline Reactive aggression & $-.13^{*}$ & -.11 & $-.20^{* *}$ \\
\hline Proactive aggression & -.12 & .01 & .09 \\
\hline$\Delta R^{2}$ & $.05^{* * *}$ & .01 & $.03^{* *}$ \\
\hline \multicolumn{4}{|l|}{ Step 3} \\
\hline Gender & .08 & $.11^{*}$ & $.10^{*}$ \\
\hline Age & .01 & -.04 & -.03 \\
\hline Reactive aggression & -.09 & -.06 & $-.16^{*}$ \\
\hline Proactive aggression & -.07 & -.01 & .08 \\
\hline Empathic concern & $.18^{* *}$ & .00 & .01 \\
\hline Personal distress & $-.31^{* * *}$ & $-.19^{* *}$ & $-.16^{*}$ \\
\hline Fantasy & .04 & -.07 & -.04 \\
\hline Perspective-taking & .05 & -.01 & .00 \\
\hline$\Delta R^{2}$ & $.09^{* * *}$ & $.04^{* *}$ & $.02^{*}$ \\
\hline Total $R^{2}$ & $.14^{* * *}$ & $.05^{* *}$ & $.05^{*}$ \\
\hline
\end{tabular}

Note: $\beta=$ standardized regression coefficients values, $R=$ multiple multiple regression coefficients, $R^{2}=$ coefficient of determination, $\Delta R^{2}=$ the change in $R^{2}$ relative to the previous step in the regression ${ }^{*} p<.05,{ }^{* *} p<.01,{ }^{* * *} p<.001$

\subsection{Proactive aggression as a moderator of the relations between empathy and life satisfaction}

In order to investigate the moderation effect of aggression on the relationship between the empathy and subjective well-being components, a hierarchical linear regression model was performed with subjective well-being components as the criteria. Aggression dimensions and empathy components were entered as predictors in Step 1, and the eight interactions (reactive aggression $\mathrm{x}$ empathic concern, reactive aggression $\mathrm{x}$ personal distress, reactive aggression $x$ fantasy, reactive aggression $x$ perspective-taking, proactive aggression $\mathrm{x}$ empathic concern, proactive aggression $\mathrm{x}$ personal distress, proactive aggression $x$ fantasy, proactive aggression $x$ perspective-taking) were entered in Step 2. 
In all models, gender and age were entered as predictors in Step 1 as control variables. A significant increase in $\mathrm{R}^{2}$ in the second step would indicate a moderator role of aggression on the relationship of empathy and subjective well-being components. Several moderation effects have emerged. Proactive aggression was a moderator for the relationship between empatic concern and overall life satisfaction, and empatic concern and overall happiness.

With increasing scores on proactive aggression, relations between empathy concern and overall life satisfaction $(\beta=-.17, p=.04)$ (Figure 1$)$, and empathic concern and overall happiness $(\beta=-.20, p=.02)$ (Figure 2$)$ became less positive.

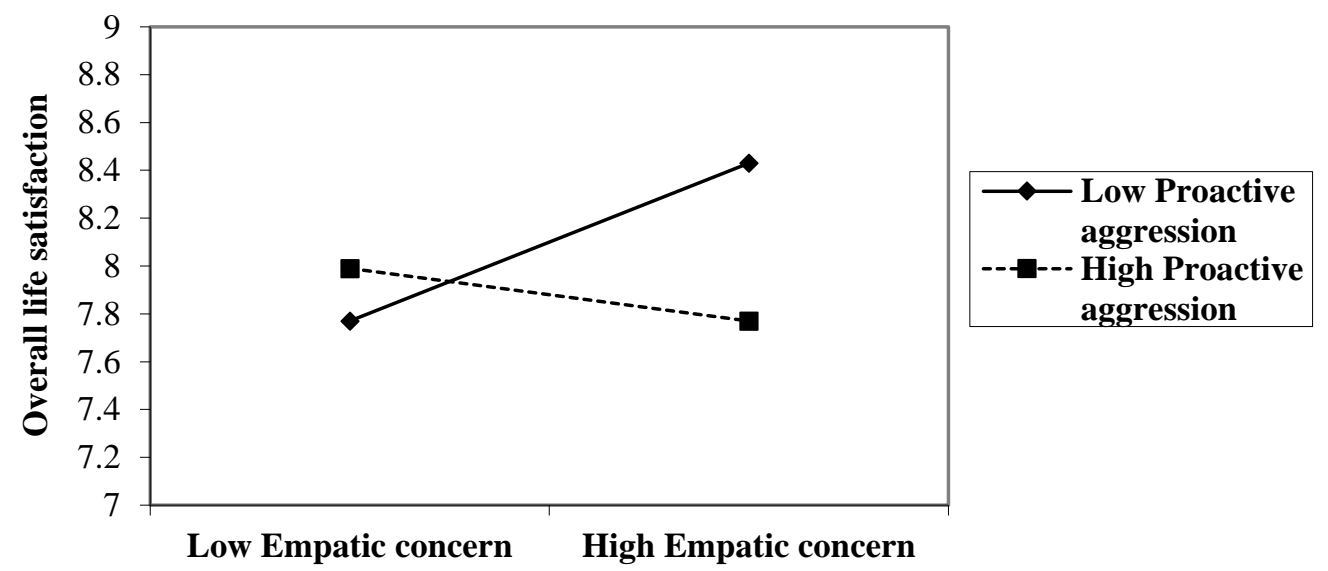

Figure 1: Moderation effect of proactive aggression on the relationship between the empatic concern and overall life satisfaction

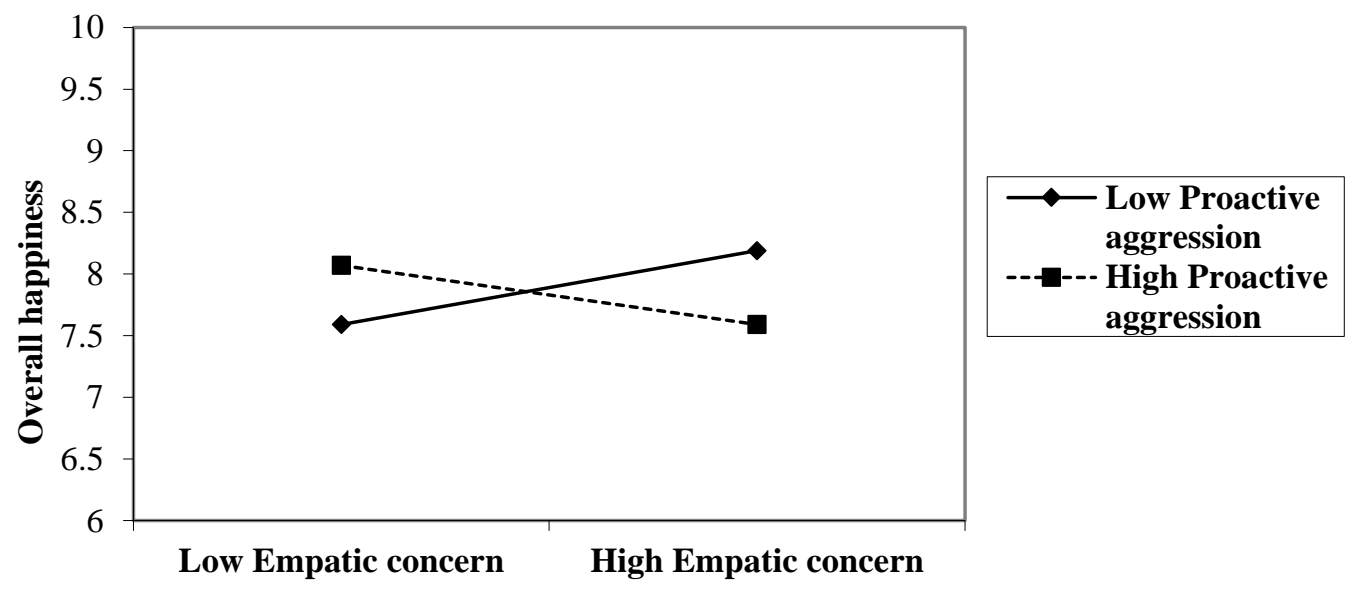

Figure 2: Moderation effect of proactive aggression on the relationship between the empatic concern and overall happiness

As we can seen on the Figure 3, with high scores on proactive aggression relationship between personall distress and overall happiness became more positive $(\beta=$ $.16, \mathrm{p}=.03)$. 


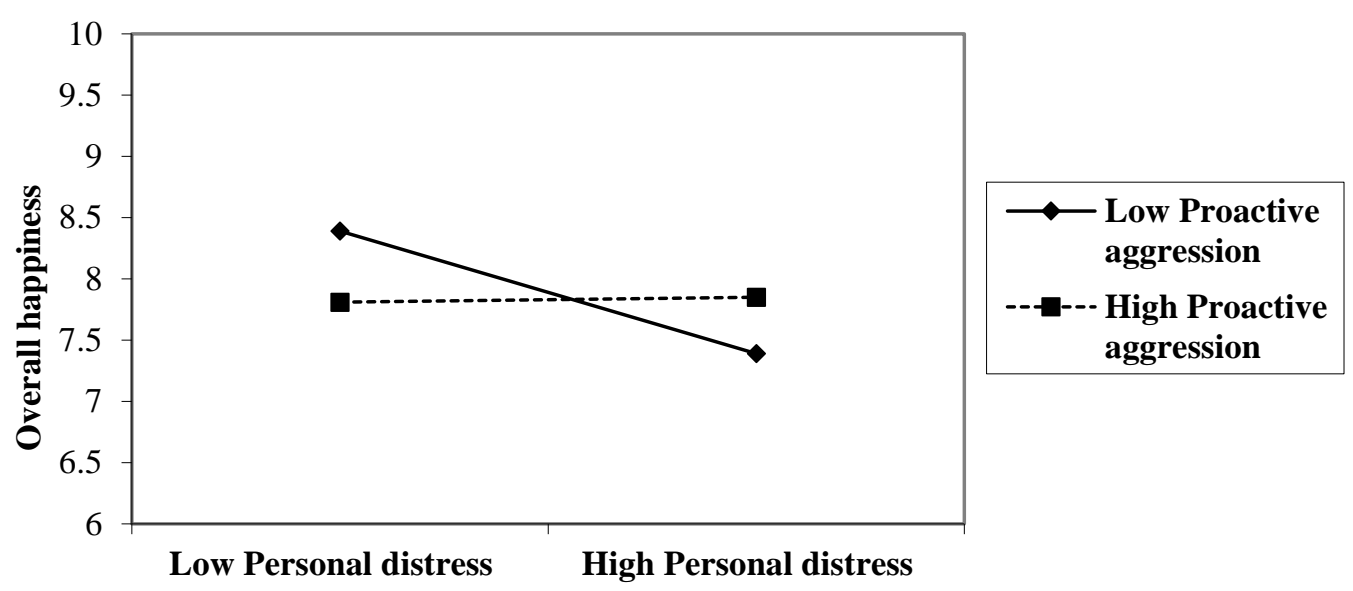

Figure 3: Moderation effect of proactive aggression on the relationship between the personall distress and overall happiness

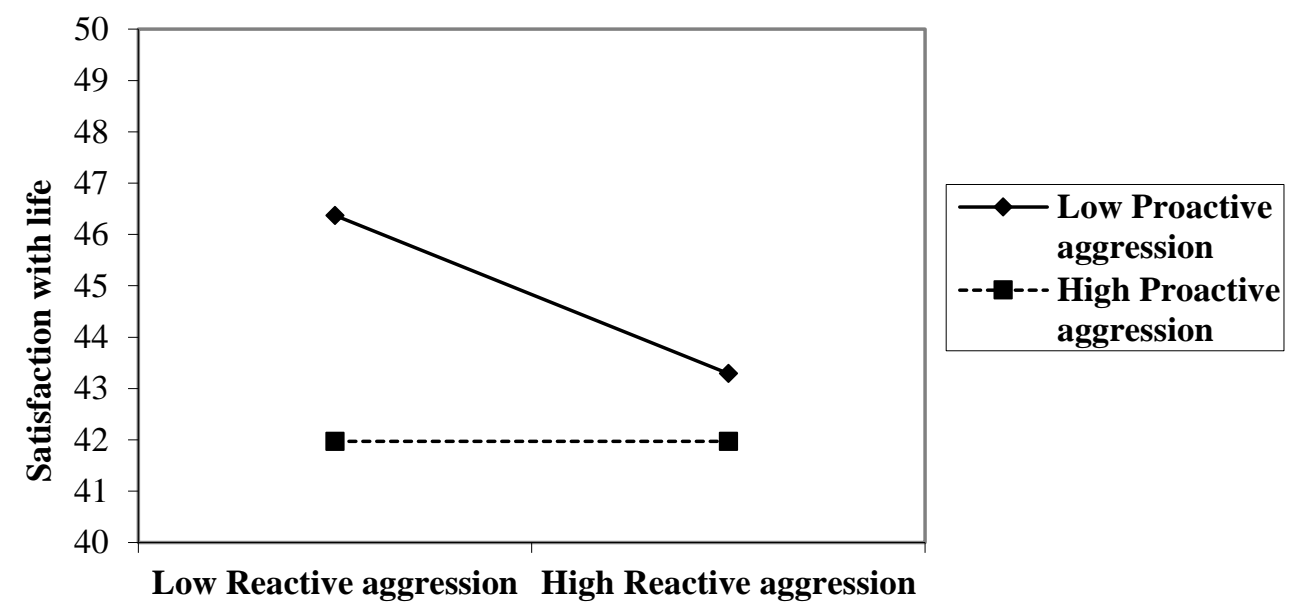

Figure 4: Moderation effect of proactive aggression on the relationship between reactive aggression concern and satisfaction with life

The proactive aggression $\mathrm{x}$ reactive aggresion interaction was significant for satisfaction with life $(\beta=.17, p=.004)$, with significant increase of $R^{2}$ in the second step $\left(\Delta R^{2}=.02, \mathrm{p}<.01\right)$ (see Figure 4$)$. This interactions indicate that the effect of reactive aggression on satisfaction with life is enervate in high proactive aggression condition.

\section{Discussion}

The present study examined the relationships between reactive and proactive aggression, emotional and cognitive components of empathy and indicators of life satisfaction. Also, this study has explored the role of empathy above aggression in the prediction of life satisfaction and the interacting effect of proactive and reactive aggression on the relationship between empathy components and indicators of life satisfaction. Reactive aggression showed a negative effect on satisfaction with life and overall happiness, which 
is in line with our prediction and findings that reactive aggression is related to harmful outcomes, sociocognitive deficits, lack of social skills, and disturbed interpersonal relationships (Pechorro et al., 2015; Poulin \& Boivin, 2000). In line with prediction, the result showed a negative relationship between proactive aggression and satisfaction with life on the bivariate level. However, this relationship dropped to nonsignificance in regression analyses, thereby suggesting that the zero-order correlation between proactive aggression and satisfaction with life was attributable to the overlap of reactive and proactive aggression. The absence of the expected negative association of proactive aggression with life satisfaction indicators may be due to proactive aggression being mainly oriented to materialistic goals, and measured of life satisfaction used in the present study includes primarily emotional responses on different aspects of life conditions (Pavot \& Diner, 1993; Pavot \& Diner, 2008). Besides, proactive aggression is associated with hedonistic values, which include the pursuit of a high standard of living and social power, often in the context of exploiting others (Sokić, 2020).

Among the empathy dimensions, personal distress showed a negative effect on all three indicators of life satisfaction. These results are consistent with our hypothesis based on the conception of personal distress as involving anxiety and low self-esteem (Davis, 1980; Davis, 1983). Expected positive association of empathy concern and satisfaction with life confirmed the theoretical assumption that empathic concern represents positive feelings of warmth and sympathy for others, sensitivity, and emotionality (Davis, 1983). It should be emphasised that empathy concern uniquely positively predicted satisfaction with life, which indicates the adaptive potential of this dimension of emotional empathy. In line with our hypothesis, perspective-taking was positively related to satisfaction in life on a bivariate level. This relationship has become nonsignificance in regression analyses which suggests that the bivariate correlation between perspective-taking and satisfaction with life results from overlapping between different empathy dimensions. Namely, it should be noted that a significant positive correlation between perspectivetaking and empathic concern was found.

Empathy dimensions added incremental variance in explaining all indicators of life satisfaction after controlling for aggression. These results indicate that empathy outperforms aggression in predicting life satisfaction.

Furthermore, the results revealed a moderation effect of proactive aggression on the relations between empathy concern and overall life satisfaction as well as overall happiness. It has been shown that relations between empathy concern and overall life satisfaction and empathic concern and overall happiness became less positive on high scores on proactive aggression. Contrary to that, with high scores on proactive aggression relationship between personal distress and overall happiness became more positive. These results indicate that proactive aggression negatively affected relationships between empathic concern and indicators of life satisfaction, while the impact of proactive aggression on the relationship between personal distress and overall happiness was positive. 


\section{Conclusion}

Taken together, the results of this study indicate that there is a significant impact of aggression and empathy on life satisfaction. Reactive aggression is a strong risk factor for satisfaction with life and overall happiness. Empathic concern has adaptive potential and represents a protective factor for efficiently using emotions, while personal distress has shown maladaptive potential for personal well-being. These results could be useful for designing separate prevention and intervention programs to help students regulate and use emotions in an adaptive, useful way.

\subsection{Limitations and future directions}

The findings of this study should be considered bearing some limitations in mind. Firstly, participants were recruited online, and the study sample consisted of a fairly homogeneous private higher education students. This way of conducting research greatly reduces the possibility of sample control so that, in fact, we do not know whether the data on sociodemographic characteristics are true. Although such a sample may be appropriate for investigating continuous relations between aggression, empathy and life satisfaction, additional studies with other samples are needed. it would be useful to repeat this research at a similar age of the forensic or prison population and on a sample from the general population.

Therefore, although our findings provide preliminary support, they cannot be generalized to the other populations. The present study employed short self-report measures of the aggression, empathy and satisfaction with life, which could have affected socially desirable responsiveness in an effort to present themselves in a favourable light. To clarify the nature of different functions of aggression and their links to empathy, it is necessary to use other measures of these psychological constructs, primarily behavioural measures. In addition, the study was conducted during social isolation caused by the COVID-19 pandemic, which has drastically affected lifestyles. These circumstances could have contributed to increased frustration and stress levels in participants, and thus to increased scores on reactive aggression and personal distress. Therefore, it is proposed that public health institutions in cooperation with higher education institutions, ensure the provision of quality and timely psychological services in order to avoid the consequences of long-term social isolation.

\section{Funding Statement}

This research did not receive any specific grant from funding agencies in the public, commercial, or not-for-profit sectors.

\section{Conflict of Interest Statement}

The authors declare no conflicts of interests. 


\begin{abstract}
About the Authors
Dr. Katarina Sokić, PhD in Psychology, MSc in Civil Law, Research Associate, Oxford Business College, 65 George Street, Oxford, United Kingdom.

Dr. Fayyaz Hussain Qureshi, BA, (Economics and Journalism); BSc (Botany, Zoology and Chemistry); MA (English Literature); MBA (Marketing); MBA (Finance); MSc (Internet Technologies); Doctorate in Marketing; PGD (Organisations Knowledge); Director of Research and Quality Assurance; Oxford Business College, 65 George Street, Oxford, United Kingdom.
\end{abstract}

Sarwar Khawaja, MBA, LLM, Chairman Business Development, Oxford Business College, 65 George Street, Oxford, United Kingdom.

\title{
References
}

Abdel-Khalek, A. M. (2006). Measuring happiness with a single-item scale. Social behaviour and personality, 34(2), 139-150. https://doi.org/10.2224/sbp.2006.34.2.139

Alorani, O. I., \& Alradaydeh, M. F. (2017). Depression, Aggression and Spiritual WellBeing Among The University Students In Jordan. European Scientific Journal, 13(2), 269-280. http://dx.doi.org/10.19044/esj.2016.v13n2p269

Barlett, C. P. (2016). Exploring the correlations between emerging adulthood, Dark Triad traits, and aggressive behavior. Personality and Individual Differences, 101, 293-298. http://dx.doi.org/10.1016/j.paid.2016.05.061

Çevik, G. B. (2017). Examining University Students' Anger and Satisfaction with Life. Journal of Education and Practice, 8(7), 187-195. ISSN 2222-288X (Online)

Cima, M., Raine, A., Meesters, C. i Popma, A. (2013). Validation of the Dutch Reactive Proactive Questionnaire (RPQ): Differential correlates of reactive and proactive aggression from childhood to adulthood. Aggressive Behavior, 39, 99-113. https://doi.org/10.1002/ab.21458

Coie, J. D., \& Dodge, K. A. (1997). Aggression and antisocial behavior. U: P. Mussen, W. Damon i N. Eisenberg (Ur.), Handbook of Child Psychology (5th ed.): Vol. 3. Social, emotional and personality development (str. 779-862). New York: Wiley.

Crick, N. R., \& Grotpeter, J. K. (1995). Relational Aggression, Gender, and SocialPsychological Adjustment. Child Development, 66, 710-722. http://dx.doi.org/10.2307/1131945

Davis, M. H. (1980). A multidimensional approach to individual differences in empathy. JSAS Catalog of Selected Documents in Psychology, 10, 85.

Davis, M. H. (1983). Measuring individual differences in empathy: Evidence for a multidimensional approach. Journal of Personality and Social Psychology, 44(1), 113126. https://doi.org/10.1037//0022-3514.44.1.113

Davis, M. H., \& Franzoi, S. L. (1991). Stability and change in adolescent self-consciousness and empathy. Journal of Research in Personality, 25, 70-87. https://doi.org/10.1016/0092-6566(91)90006-C 
Diener, E, \& Seligman, M. E. P. (2002). Very Happy People. Psychological Science, 13, 8184. https://doi.org/10.1111/1467-9280.00415

Dinić, B. M., \& Wertag, A. (2018). Effects of Dark Triad and HEXACO traits on reactive/proactive aggression: Exploring the gender differences. Personality and Individual Differences, 123, 44-49. https://doi.org/10.1016/j.paid.2017.11.003

Dollard, J., \& Ford, C. (1939). Frustration and aggression. New Haven: Yale University Press.

Duong, C. D. (2021). The impact of fear and anxiety of Covid-19 on life satisfaction Psychological distress and sleep disturbance as mediators. Personality and Individual Differences, 178, 110869, https://doi.org/10.1016/j.paid.2021.110869

Evans, S., Alkan, E., Bhangoo, J. K., Tenenbaum, H., \& Ng-Knight, T. (2021). Effects of the COVID-19 lockdown on mental health, wellbeing, sleep, and alcohol use in a UK student sample. Psychiatry Research, 298:113819, PMID: 33640864, https://doi.org/10.1016/j.psychres.2021.113819

Frick, P. J., Cornell, A. H., Barry, C. T., Bodin, S. D., \& Dane, H. E. (2003). Callousunemotional traits and conduct problems in the prediction of conduct problem severity, aggression, and self-report of delinquency. Journal of Abnormal Child Psychology, 31 (4), 457-470. https://doi.org/10.1023/a:1023899703866

Hare, R. D., Cooke D. J., \& Hart, S. D.. 1999. Psychopathy and sadistic personality disorder. In: Millon T, Blaney PH (eds). Oxford Textbook of Psychopathology. Vol. 4. London: Oxford University Press. pp 555-584

Hojat, M., Vergare, M., Isenberg, G., Cohen, M., \& Spandorfer J. (2015). Underlying construct of empathy, optimism, and burnout in medical students. International Journal of Medical Education, 6, 12-16, PMID: 25633650, https://doi.org/10.5116/ijme.54c3.60cd

Hu, Y., Ye, B., \& Im, H. (2021). Hope and post-stress growth during COVID-19 pandemic: The mediating role of perceived stress and the moderating role of empathy. Personality and Individual Differences, 178, 110831. https://doi.org/10.1016/j.paid.2021.110831

Lawrence, E. J., Shaw, P., Baker, D., Baron-Cohen, S., \& David, A. S. (2004). Measuring empathy: reliability and validity of the Empathy Quotient. Psychological Medicine, 34, 911-924. https://doi.org/10.1017/S0033291703001624

O'Connor, R. C., Wetherall, K., Cleare, S., McClelland, H., Melson, A. J., Niedzwiedz, C. L. Robb, K. A., ... (2020). Mental health and well-being during the COVID-19 pandemic: Longitudinal analyses of adults in the UK COVID-19 Mental Health \& Wellbeing study. The British Journal of Psychiatry, 218(6), 326-333. https://doi.org/doi:10.1192/bjp.2020.212

Ozcakir, A., Ediz, B., \& Bilgel, N. (2016). The relationship between subjective well-being and empathy among Turkish medical students. MedEdPublish, 1-25, http://dx.doi.org/10.15694/mep.2016.000059

Paro, H. B. M. S., Silveira, P. S. P., Perotta, B., Gannam, S., Enns, S. C., Giaxa, R. R. B., et al. (2014). Empathy among medical students: is there a relation with quality of life 


and burnout? PMID: 24705887; PMCID: PMC3976378.

http://dx.doi.org/10.1371/journal.pone.0094133

Patrick, C. J. 2001. Emotional processes in psychopathy. In Raine A, Sanmartin J (eds): 'Violence and Psychopathy.' New York: Kluwer/Plenum, pp 57-77

Pavot, W., \& Diener, E. (1993). Review of the satisfaction with life scale. Psychological Assessment, 5, 164-172. https://doi.org/10.1037/1040-3590.5.2.164

Pavot, W., \& Diener, E. (2008). The satisfaction with life scale and the emerging construct of Life satisfaction. Journal of Positive Psychology, 3, 137-152. http://dx.doi.org/10.1080/17439760701756946

Pechorro, P., Ray, J. V., Raine, A., Maroco, J., Goncalves, R. A. (2015). The ReactiveProactive Aggression Questionnaire: Validation Among a Portuguese Sample of Incarcerated Juvenile Delinquents. Journal of Interpersonal Violence, 0886260515590784. https://doi.org/10.1177/0886260515590784

Poulin, F., \& Boivin, M. (2000). Reactive and proactive aggression: Evidence of a twofactor model. Psychological Assessment, 12(2), 115-122. http://dx.doi.org/10.1037/1040-3590.12.2.115

Qureshi, F. H., Khawaja, S., \& Zia, T. (2020). Mature undergraduate students' satisfaction with online teaching during the COVID-19. European Journal of Education Studies, 7 (12), 456-475. http://dx.doi.org/10.46827/ejes.v7i12.3440

Raine, A., Dodge, K., Loeber, R., Gatzke-Kopp, L., Lynam, D., Reynolds, C., . . Liu, J. (2006). The reactive-proactive aggression questionnaire: differential correlates of reactive and proactive aggression in adolescent boys. Aggressive Behavior, 32(2), 159-171. https://doi.org/10.1002/ab.20115

Shamay-Tsoory, S. G., Aharon-Peretz, J., \& Perry, D. (2009). Two systems for empathy: A double dissociation between emotional and cognitive empathy in inferior frontal gyrus versus ventromedial prefrontal lesions. Brain, 12, 617-627. https://doi.org/doi:10.1093/brain/awn279

Sokić, K. (2020). The role of values in reactive and proactive aggression // Proceedings of the XXVI scientific conference empirical studies in psychology / Videnović, M., Stepanović Ilić, I., Simić, N., Rajić, M. (ur.). Beograd: Institute of Psychology, Faculty of Philosophy, University of Belgrade, pp. 40-42. ISBN 978-86-6427-165-3

Sokić, K. (2017). Examination of the Triarchic model of psychopathy. Unpublishead doctoral thesis. University of Zagreb, Croatia, Faculty of Humanities and Social Sciences. Retrived from: http://darhiv.ffzg.unizg.hr/id/eprint/9239/

Sokić, K., \& Wertag, A. (2018). Examing the effects of disinhibition in understanding empathy and attachemen, in Damnjanović, K. (Ed.), 24th Scientific Conference Empirical Studies in Psychology, 23-25 March, Faculty of Philosophy, University of Belgrade, pp. 43-45.

Vittinghoff, E., Glidden, D. V., Shiboski, S. C., \& McCulloch, C. E. (2012). Regression methods in biostatistics: Linear, logistic, survival, and repeated measures models (2nd edition). Springer. https://doi.org/10.1007/978-1-4614-1353-0 
White, H. A. (2021). Need for cognitive closure predicts stress and anxiety of college students during COVID-19 pandemic. Personality and Individual Differences, 111393, ISSN 0191-8869, https://doi.org/10.1016/j.paid.2021.111393 
Creative Commons licensing terms

Author(s) will retain the copyright of their published articles agreeing that a Creative Commons Attribution 4.0 International License (CC BY 4.0) terms will be applied to their work. Under the terms of this license, no permission is required from the author(s) or publisher for members of the community to copy, distribute, transmit or adapt the article content, providing a proper, prominent and unambiguous attribution to the authors in a manner that makes clear that the materials are being reused under permission of a Creative Commons License. Views, opinions and conclusions expressed in this research article are views, opinions and conclusions of the author(s). Open Access Publishing Group and European Journal of Education Studies shall not be responsible or answerable for any loss, damage or liability caused in relation to/arising out of conflicts of interest, copyright violations and inappropriate or inaccurate use of any kind content related or integrated into the research work. All the published works are meeting the Open Access Publishing requirements and can be freely accessed, shared, modified, distributed and used in educational, commercial and non-commercial purposes under a Creative Commons Attribution 4.0 International License (CC BY 4.0). 